thing in the shape of malignancy, for which excision may not be practised. It may be done for even extensive necrosis ; indeed we can call to mind other instances besides the subjoined wherein Mr. Fergusson adopted this mode of treatment with decided advantage; and we have the recent experiments of $M$. Ollier, of Lyons, to prove that if the periosteum be left entire in the vicinity of joints, it will reproduce bone.

At one time the patella was allowed to remain, because it added support and strength to the knee; but subsequent experience has tended to show the advantage of its removal. Its retention is still a subject for consideration.

There are several examples of excised knees at the present time under treatment, independently of those which we bring forward to-day. Amongst them is a patient in King's College Hospital, upon whom Mr. Henry Lee performed the operation on the 30th June; and another, a girl in the London Hospital, operated upon by Mr. Curling on the 21st June. To show the rapidity with which the parts unite after excision, we may mention that a patient whose elbow was excised by MIr. Curling on the 28th of June by means of the longitudinal incision, hac the wound perfectly united within a fortnight. We have known such speedy results to occur in the knee.

The greatinducement to perform excision of the knee-joint at the present day is the fact that the per-centage of deaths consequent on this operation is much less than that attending amputation; a reference to the memoirs of Mr. Butcher and Mr. Price will satisfactorily prove the truth of this. At Guy's Hospital, Mr. Bryant has shown, the per-centage of deaths in pathological amputations is 1 in $5 \cdot 5$, the same as in excision of the knee; whilst that in chronic disease is 1 in 7 , being somewhat more favourable. The statistics of amputations elsewhere, taken generally, will not give such favourable results as these.

The notes of the following case were furnished by Mr. Francis Mason, late house-surgeon to the hospital.

E. $\mathrm{H} \longrightarrow$ aged fourteen, was admitted Dec. 27 th, 1859. He stated that in May, 1858, he was being carried down some steps, when his knee came in contact with the iron railings; the joint was slightly painful at the time, but he thought little of it, and it improved by fomentations and rest. About six weeks after the accident, however, he experienced a good deal of sharp, shooting pain in the joint, with considerable swelling. He sought medical advice, but no remedies appeared to have beneficial effect upon it. This state of things continued three months, when an abscess was discovered to exist in the joint, which was opened, and an immense quantity of matter evacuated. This gave him some temporary relief, but the lnee had now become considerably flexed, obliging him to adopt crutches to enable him to get about. He continued much in this state up to the time of admission.

The patient is a pale, delieate, strumons-looking boy. $\mathrm{He}$ lies on his left side; the thigh being flexed on the trunk, the leg on the thigh. There are several sinuses in the region of the joint leading to bone; one, on the inner and lower part of the thigh, leads to an extensive bare surface of the femur. The patient has no brothers or sisters; father and mother healthy. No lung affection; other functions of the body natural.

Jan. 7 th. -..'The patient having been narcotized, Mr. Fergus son proceeded to remove a piece of the shaft of the femur about six inches in length, by an incision of two inches, made at the lower end of the thigh. The removed portion was easily de. tached, and found to be necrosed.

8th. - Has had a good night; complains of slight thirst limb rather uncomfortable; pulse 106.

10th. - Wound suppurating healthily; the patient says the limb is not so painful as before the operation; appetite good.

Feb. 2nd. - Has gone on well since last report; eats, drinks, and sleeps well; is anxious to have his leg put straight.

March 3rd. - To-day the operation of excision of the kneejoint was performed by Mr. Fergusson, the patient being under the influence of chloroform. The $\mathrm{m}$ incision having been made in the integuments, sufficient of the ends of the femur and tibia was cut off to bring the limb in the straight position. The patella was removed. There was very little hæmorrhage during the operation, no vessel requiring a ligature. A splint having been applied, the patient was sent to bed.

4th. - Has had a restless night, the limb having been very painful, but the pain has been much mitigated by an opiate draught; pulse 120

5tin.--Is much better to-day in health, but the leg continues to give great pain at intervals. To have three grains of sesquicarbonate of ammonia in an ounce of decoction of cinchona every four hours.

loth. - Wound discharging healthily; no bad symptom; appetite good ; bowels regular; all pain has disappeared.

20th. - Is still going on well, the wound discharging a thin, serous fluid, mixed with pus; splint removed; the joint seems firm ; splint reapplied.

May lst.--Gutta-percha splint applied to the back of the leg. 9th.-Discharged to go into the country.

\section{ST. THOMAS'S HOSPITAL.}

SIX CASES OF EXCISION OF THE KNEE-JOINT, PERFORMED IN 1859 , FOLLOWED BY RECOVERY IN FIVE.

(Under the care of Mr. SotTh, Mr. SoLLY, Mr. LE GRos GLARK, and Mr. Simon.)

THE operation was performed in pretty much the same manner in all of the following cases, as we learn from Mr. Allingham, Surgical Registrar to the hospital, to whom we are indebted for their brief details. Chloroform was given, and the joint was opened by an elliptic incision, which included the patella in the flap. The ends of the bones and the joint surface of the patella were removed by Butcher's saw, and the limb was put up in a slightly bent iron back splint. Liberal diet and stimulants were given, and all the patients had cod. liver oil and some preparation of iron.

CASE 1.-A strumous, delicate man, aged thirty-seven; had disease of the sternum and nlceration of the cartilages of the left knee-joint. He suffered much pain, his rest was disturbed, appetite bad, and his health generally broken. Two sinuses, connected with the joint, discharged a watery pris, Excision was performed by Mr. South Nov. 5th, 1859. The cartilages were found extensively eroded, and the head of the tibia secondarily affected to a slight extent. At first, after the operation, his health improved; the wound united in part, and healthy suppuration was established: but towards the end of February diarrhcea of a very obstinate character set in, with night-sweats. By the end of Narch his condition was by no means satisfactory; there was no apparent union of the bones, his diarrhcea continued despite the use of various astringents, he was sick at times, and his appetite was capricious. The wound did not discharge excessively, and it looked healthy. From this time there was but little alteration in his condition, and certainly none for the better, and he went out, at his own particular request, on the 2 nd of June. There was then no amount of bony union, the wound was discharging a tolerably healthy pus, and he did not suffer pain. He died a short time after leaving the hospital.

CASE 2. - A very strumous-looking boy, aged six, with chronic ulceration of the cartilages of the right knee-joint, the tibia being dislocated backwards. He was hectic; suffered much pain; and there was a discharging sinus connected with the joint. Excision was performed by Mir. Solly on the 9th of November, 1859. The cartilages were extensively eroded and the ligaments destroyed. After the operation he improved at once, never having a bad symptom. The wound lealed; he gained health and strength, and left the hospital with searcely any perceptible shortening of the limb, being able to walk with ease and comfort.

CASE 3.- A delicate, scrofulous boy, aged eight, with chronic ulceration of the cartilages of the knee-joint; free discharge from three sinuses. He was hectic, and suffered much pain. Excision was performed on the 5th of March, 1859, by Mr. Solly. There was considerable erosion of the cartilages, and false membrane in large quantities; but no disease of bone. The wound united in great part by first intention; his health improved; he slept well; and his appetite was excellent. He left the hospital quite stout and well; the limb was only half an inch shorter than its fellow, and he could walk with ease and rapidity.

CASE 4.-A strumous boy, aged twelve, with long-standing suppuration in the knee-joint and several discharging sinuses. He was much out of health, and suffered greatly. Excision was performed by Mr. Le Gros Clark on the 12th of March, 1859. The cartilages were found to be in great part removed, and there was some secondary disease of the head of the tibia. A considerable portion of the wound united by primary inten. tion. He slept well, and took his food with relish. During the progress of the case he had a slight attack of erysipelas, and an abscess formed over the ankle. Despite these drawbacks, the result of the case was favourable; and when he left the hospital there was firm bony union, and only a small portion of the wound uncicatrized. The limb was but slightly shortened.

CASE 5.-An emaciated, sickly girl, aged six, with scrofulons disease of the knee-joint. She had suffered much; slept badly; and had but little appetite. Excision performed Nov. 12th, 
1859, by Mr. Simon. The cartilages were eroded, and there was softening of the end of the femur. For a few days after the operation her condition was very critical, but when suppuration was established she improved, slept better, and was more cheerful. She was sent from the hospital to the Margate Infirmary. There was firm bony union, and only a slight amount of ulceration in the line of the incision when she left St. Thomas's.

CASE 6.-An unhealthy, pasty-looking man, aged twentythree, with long-standing disease of the knee-joint. After his admission two incisions were made, and considerable quantities of pus escaped. He did not improve much, and excision was performed Nov. 19 th, 1859, by Mr. Simon. There was extensive ulceration of the cartilages, and superficial caries, dependent upon a small sequestrum in the head of the tibia. $\mathrm{He}$ improved in health after the operation, and a good deal of the wound united by first intention. A counter opening was required, when suppuration occurred, to give exit to some retained pus. When he left the hospital there was firm union of the bones, he was able to get about, and was in very fair health.

\section{ROYAL FREE HOSPITAL.}

STRUMOUS DISEASE OF THE KNEE-JOINT ; EXCISION; RECOVERY WITH A SOUND, ANCHYLOSED, AND USEFUL LIMB.

(Under the care of Mr. GANr.)

THE two following cases sufficiently speak for themselves. They make up the nine mentioned in our previous remarks, and with but one unsuccessful resuit out of that number:-

John $\mathrm{P} \longrightarrow$, aged eighteen, was admitted on Oct. 19th, 1859. The patient is a strumous, unhealthy-looking subject; a coalporter. While following his occupation about four years and $\mathbf{a}$ half ago, a large piece of coal fell on his right knee, and occasioned pain for some days, after which he resumed his work, although the joint was much swollen, and still painful. $\mathrm{He}$ continued to work during the ensuing three months, the joint remaining swollen, and latterly the hamstring muscles contracted so as to draw the limb backwards to nearly a right angle with the femur. He then went under treatment at the Westminster Dispensary for four months, during which period the muscies gradually drew the heel up to the buttock. He afterwards resorted to St. George's Hospital, where he experienced some relief, under the care of Mr. Hawkins, and was discharged at the end of three months. Thence he went to St. Mary's Hospital, and was a patient for more than eight weeks, under the care of Mr. Lane. Subsequently, at the Westminster Hospital, he remained for ten months, under the care of Mr. Guthrie, when he was discharged. After six months' suffering, he was again admitted into the same hos pital, and continued under treatment for two months more. At length he sought relief at the Middlesex Hospital; but having remained for three months, without any improvement, he left the hospital. Eventually he came to the Royal Free Hospital, and was placed under the care of Mr. Gant on the 19th of October last.

The joint was found to be uniformly swollen, but not so much as to obscure its outline. A thin unhealthy discharge issued from two or three sinuses which led into the joint, and the patient was much emaciated. His general health having been renovated so far as the local disease and lengthened illness allowed, Mr. Gant excised the joint under chloroform on Oct. 31st. By a transverse and slightly curved incision below the patella, and extending from one condyle of the femur to the other, the joint was fairly laid open. The patella was then removed, although in a sound condition, and a slice of the femur and tibia, both of which were partially bare of cartilage, were sawn off. The femur was most diseased, and a second slice was taken from it, until the rose-coloured bleeding bone was reached. All the disèased bone having been thus got rid of, the surfaces of the femur and tibia were seen to be well ad. justed to each other, and the edges of the incision brought together with sutures of fine silver wire. No vessel required ligature. The limb was at once placed upon an extended Macintyre splint, of such length as to allow of the femur and tibia to be in easy apposition withont being much pressed together by the foot-board. Broad strips of adhesive plaster were then drawn around the limb, a splint applied above and below the knee, and a bandage from the foot upwards and from the thigh downwards, leaving the knee uncovered, around which were placed strips of wet lint. No side splint was used.
No unfavourable or unusual symptom followed the operation. On the eighth day some hæmorrhage occurred, which was arrested by the application of ice.

Dec. 17 th. - The splint was removed, and union found to have taken place; the limb was replaced; general health much improved.

Jan. 2nd. - Union was more firm; health continues to improve, and his trembling agitation has subsided.

27th.--Union more firm; limb replaced on a short posterior splint.

From this time the patient sat up in bed daily, but it was deemed advisable not to allow him to try the leg much. When the weather became warmer, he took gentle exercise, with his leg suspended in a sling. He left the hospital with a sound and useful limb, having been allowed to remain an in-patient until he could be admitted into the Margate Infirmary to thoroughly re-establish his health.

\section{EXTENSIVE CARIES OF THE RIGHT KNEE-JOINT;}

EXCISION; RECOVERY, WITH FIRM ANCHYLOSIS, IN TWO MONTHS.

(Under the care of Mr. GANT.)

Elizabeth D__, aged thirty-three, married, on Septem: ber $29 \mathrm{th}$, 1853, while walking down a gentle descent, slipped over some rotten pears, and caught the heel of her boot in a grating, whereby the knee was wrenched inwards, causing severe pain. Considerable swelling ensued, which never subsided; but the articulation continued movable for three months, at which time, the patient having scrubbed two or three rooms, more intense pain attacked the joint, which soon became fixed. This crippled state continued without any improvement, although leeches and blisters were used from time to time after the injury. The general health remained unimpaired up to October, 1858 , when she experienced severe pain, apparently rheumatic, extending throughout the whole limb. This subsided under treatment, but the practitioner to whom she had last applied candidly told her that the case was incurable otherwise than by amputation; and by his recommendation she eame to the Royal Free Hospital on September 12th, 1859.

The joint was considerably and uniformly swollen. Three sinuses, one in the popliteal space, discharged a thin ichorous matter, and the limb was bent towards the buttock, but was movable with a grating noise, such as plainly bespoke destruction of the articular surfaces. The constitutional irritation was proportionate to the six years' suffering the patient had endured. She was not so much emaciated, but passed sleepless nights, trembled, and was always in tears.

On October 19th, chloroform having been administered, $\mathrm{Mr}$. Gant excised the joint by making the same incision as in the preceding case. The head of the tibia was saw $n$ off to the depth of half an inch; a thicker portion of the femur was taken away, and the cancellated structure scooped out for more than an inch, so as entirely to remove all diseased bone. The patella was also removed. The subsequent steps of the operation and adjustment of the splint were precisely similar to those adopted in the o: her case.

The general health improved rapidly after this operation. The patient gained flesh and spirits, and progressed without a single unfavourable symptom. At the end of tight weeks the splint was finally removed, and so firm was the anchylosis that no other was applied, the limb being merely bandaged from the toes upwards to prevent any tendency to swelling on first moving about.

The patient could rest her whole weight on the operated limb, and she left the hospital in time to eat her Christmas dinner at home.

\section{CIINICA L RECORDS.}

\section{SENSATION OF CRACKLING WITHIN THE JOINTS.}

A FEMALE, aged thirty-six years, but looking much older, a housemaid, of spare frame and short stature, was admitted into St. Bartholomew's Hospital on the 6th of February last, under Dr. Farre's care, with general pains about her limbs and joints. She has been a sufferer from rheumatoid arthritis; and from her family history it appears that her father and uncle were subject to the same disease, or to gout, but which, she says, was rheumatic gout. Besides the general pain and distress present on her admission, she had a sensation of crack. ling within all the affected joints, especially well marked at the under part of the right knee, in the right ankle, in the left 